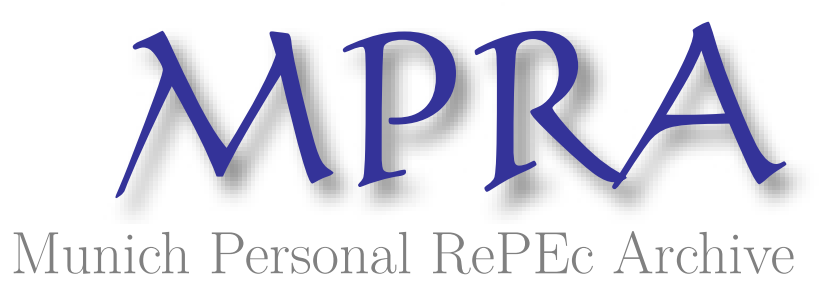

The creation of internet communities: A
brief history of on-line distribution of
working papers through NEP, 1998-2010

Batiz-Lazo, Bernardo and Krichel, Thomas

Bangor Business School, Long Island University

November 2010

Online at https://mpra.ub.uni-muenchen.de/27085/

MPRA Paper No. 27085, posted 30 Nov 2010 07:08 UTC 
[Please do not quote]

\title{
The creation of internet communities: A brief history of on-line distribution of working papers through NEP, 1998-2010'
}

Bernardo Bátiz-Lazo (University of Leicester and Bangor Business School, UK)

Thomas Krichel (Long Island University, USA and Novosibirsk State University, Russia)

November 2010 (8,213 words - including tables and references)

\begin{abstract}
This paper adds to the growing literature on the formation of online communities from an historical perspective [1-3] by telling of the emergence and development of a service for speedy, online distribution of recent additions to the broad literatures on economics and related areas called NEP: New Economics Papers as well as the online community that grew around it. We provide details of the social and technological challenges for its construction as well as the evolution of its governance. The development of NEP provides an illustrative example for the kind of new business models that have emerged as the Internet has been used by creative minds to provide existing services in a new way.
\end{abstract}

Keywords: digital libraries, online communities, open source, New Economic Papers (NEP), RePEc

\footnotetext{
${ }^{1}$ Previously circulated as 'On-line distribution of working papers through NEP: A Brief Business History' (http://ideas.repec.org/p/wpa/wuwpeh/0505002.html March 2005). Helpful comments of Damir Jelic, John S. Irons ,Antonio Tena, Leandro Prados de la Escosura, Larry Neal, Bill Russell, Jeff Yost and Thomas Haigh as well as staff presentation at Universidad Carlos III and Dundee University are gratefully acknowledged. The usual caveats apply.
} 


\section{Introduction}

There has been a growing interest to better understand the means upon which geographically disperse communities use the Internet to interact [e.g. 1, 4, 5-8]. A common theme is how once engineers developed infrastructure (i.e. software, platforms and protocols that link them), users had to build the social networks that made them useful [e.g. 2, 3, 9, 10].

Defining a community can be elusive. Akera [11] noted that different modes of community appear under different modes of operation. His taxonomy links, on the one hand, opportunities afforded by Internet-based business and services that cater for distinct communities with, on the other hand, a study of the design, adaptation and integration of information technology its social and institutional context. He identified three types of web-based communities namely converted services, brokerage services and community networking services. The latter is said to be a domain supported primarily through public funding and philanthropic activity. Indeed, the academic community across the world is very much geared up to the production of "public goods". Moreover, this community is ready to set up social institutions that help and foster freeflow of ideas, networking, association and interaction while looking to facilitate exchanges and synergy amongst people of similar interests. For instance, Krichel and Zimmerman define academic texts as "documents that authors do not expect to be paid royalties for, that are targeted towards a very specialized audience and that do not contain advertising." [12].

The case study in this paper details the emergence and key stepping stones in the evolution of the technical infrastructure supporting an online digital library of working papers and in this process add to the understanding of how technological solutions mapped to a particular academic community. This technological infrastructure was created to offer a service for speedy, on-line distribution of recent additions to the broad literatures on economics and related areas and was called NEP: New Economics Papers. ${ }^{3}$ NEP emerged as part of a wider project called RePEc: Research Papers in Economics, a digital library that facilitated distribution of contributions to the relevant scientific communities through the Internet. Another major digital library was the Social

\footnotetext{
2 "Public goods" are said to have two main characteristics, first, consumption of the good by one individual does not reduce availability of the good for consumption by others; and, second, that no-one can be effectively excluded from using the good.

${ }^{3}$ http://nep.repec.org (accessed 22 October 2010).
} 
Science Research Network (SSRN), which in the mid-1990s started to charge for accessing its services, including subscription to e-mail distribution of pre-print academic texts. NEP was born in 1998 as free of charge alternative in the digitalisation of collections of pre-print academic articles.

A combination of purpose made and free software enable NEP to achieve its aim of facilitating interaction between decentralised groups of like minded scholars and users of academic research. Open source (a.k.a. free) software was adequate (but not essential) to create a scalable model. But having the means was a necessary but insufficient condition for success because building a sophisticated community is largely a social activity. Success was contingent to reaching critical scale in the number of users and items in the digital library, sorting out issues of high fixed costs, attracting talent to develop incremental innovations and differentiation. This paper thus tells of the challenges to create a successful Internet community and the technological means to support it. These challenges included the consequences of decisions about the technical infrastructure (such as the selection of readymade vs purpose specific applications, negotiating host computers, etc.). The narrative also tells how NEP resisted attempts to develop into an online journal as a way to attract new collections and therefore, make the platform more valuable to new and prior subscribers (that is, the emergence of network externalities). But as had been the case for other online communities, as the number of subscribers, collections and editors grew, coordination required evolution and adaptation of responsibilities. In order words a move from ad hoc, fortuitous collaboration to the introduction of processes, procedures and formal governance (selection of content and editors, duties and responsibilities of general editor, role of editorial and technical board, etc.).

Fieldwork in this paper combined multiple source material to document technical developments of NEP and the online community around it. The research method goes beyond simple observation of a distributed phenomenon as we were deeply involved in creating RePEc and NEP. Through our experience we explain the history of these resources and their continuing impact. However, the research method also introduced interviews and archived documents. Following established best practice in this area we solicited views and comments on the document from other people involved in the development of NEP and RePEc. They provided their accounts separately and we conducted several rounds of drafting as the narrative grew increasingly detailed. Drafts 
were crossed checked by all participants. Alongside this process, archived documents were also gathered. ${ }^{4}$ These encompassed protocols, statement of intent, software and contemporary e-mail correspondence (both private and through discussion groups) while aiming to verify details and prompt more accurate recollections. The process of "triangulation" between personal recollection, interviews and archives eventually yielded a stable and robust narrative.

The reminder of this paper proceeds as follows, the next tells section of NEP's origins and growth in scale and scope. It also documents the evolution of its governance. The third section reflects on the case study of NEP under the light of the so called "economics of open source" framework.

\section{The Technological Infrastructure of a Current Awareness Service Origins of NEP}

NEP was conceived as initiative to go beyond the legacy model of digital library services [see 13, 14]. NEP is a human-mediated current awareness service (CAS), that is, a service that informs users of new documents within a subject of interest. Most CAS's are run by publishers or producers of specialised abstracting and indexing (A\&I) service. If the CAS is run by a publisher, it is usually limited to books, journals and other products of that publisher. If the CAS is run by an A\&l service, the CAS is only available to subscribers to that service. Most current awareness services are produced by a computer. Usually, it means that a piece of software is looking for some terms in the document or some other criteria such as the membership of a document in a certain collection. If not produced by computer, the CAS can be quite expensive to produce.

Krichel [15] identified three types of CAS, namely common classification based, keyword based and usage history based. The first refers to the computer filtering new information into pre-determined classification (such as "sports", "national politics" or "culture"). This works well as long as vocabularies in documents of different classes is very distinct (e.g. Google News). Academic information, however, tends to be difficult to

\footnotetext{
${ }^{4}$ Grier and Campbell [3]D. A. Grier, and M. Campbell, "A Social History of Bitnet and Listserv, 1985-1991," IEEE Annals of the History of Computing, vol. 22, no. 2, pp. 32-41, 2000., note the challenges to historical research of online communities include the ephemeral nature of network correspondence (such as that by chat programmes), the lack of archives of early e-mail, rapidly decaying and fast obsolesce of storage media (e.g. floppy disks). However, the apparition of email management and distribution list programmes enabled a systematic storage and archives from where a coherent picture can emerge. The ethnographic study in Ketly [9] C. M. Kelty, Two Bits: The Cultural Significance of Free Software and the Internet, Durham, NC: Duke University Press, 2008. is based on a similar method to that described above.
} 
classify. A second type of CAS is the keyword based, where a user builds up a profile of his/her interests and files it with a service provider. The provider will e-mail documents that contain those keywords (e.g. Nexis contents alert or work opportunities by jobs.ac.uk). This works well if the keywords are right. Unfortunately this is difficult for academic documents as getting the keywords right is often elusive (e.g. searching for jobs in "management" can return both openings at business schools and administrative work in universities). Thirdly, in a usage history based CAS where a system tracks account activity to build up a profile of interest of the user (e.g. suggestions at Amazon.com). It works well as long as user interests remain unchanged. But it is hard to think of a unified system to catalogue usage of academic documents that a computer could watch.

The inadequacies of computer generated CAS for academic work led to the development of human-mediates CAS. The earliest known CAS in economics dates to the efforts of Mr Fethy Mili at the University of Montreal. ${ }^{5}$ Around 1993, Mili created the first electronic announcement service of working papers. Collections of research articles deemed suitable for publication had grown in popularity as the queue for publication in peer reviewed outlets grew ever larger. Academics found in these collections a way to make available to a wider audience research which had been accepted for publication (or deemed to be of publication quality by their department). Access to these collections, however, was limited and restricted to libraries where hard copies were deposited by authoring institutions. Mili found a way to give a wider audience access to working paper collections by managing a CAS through an e-mail distribution list, in other words, he would inform of recent additions by e-mail to subscribers of his list. These additions sourced in hard copies of working papers deposited at the Library of the University of Montreal. Subscription to Mili's list was free but subscribers had to post or e-mail a request directly to the authors.

Also in 1993, Thomas Krichel $^{6}$ (then at the University of Surrey) established $\mathrm{NetEc}^{7}$, a consortium of Internet projects for academic economists. ${ }^{8}$ One important part

${ }^{5}$ The bibliographic information of these holdings was incorporated into NetEc in 1997 (http://www.economicsnetwork.ac.uk/cheer/ch11 1/ch11 1p19.htm Accessed 20/Nov/2010). 6 http://openlib.org/home/krichel/ (accessed 01/Nov/2010).

7 http://netec.mcc.ac.uk/ (accessed 25/Mar/2005).

8 Dongarra et al. [2] J. Dongarra, G. H. Golub, E. Grosse et al., "Netlib and NA-Net: Building a Scientific Computing Community," IEEE Annals of the History of Computing, vol. 30, no. 2, pp. 30-41, 2008. Tells of the evolution of a similar effort to form a digital collection of mathematical software, papers and databases in the 1980s. By the 1990s such collections seem to have 
of the NetEc consortium was WoPEc, a service for electronic working papers in economics. Between 1996 and 1999, the NetEc group received support for its WoPEc project by the Joint Information Systems Committee (JISC) of the UK Higher Education Funding Councils, as part of its Electronic Libraries Programme (eLib). In 1997, Krichel further developed WoPEc into decentralised database of working papers (i.e. recent research reports prior to formal publication), journal articles (i.e. peer reviewed writings) and software components called Research Papers in Economics or RePEc. By March 1999 RePEc had grown into an interconnected network of over 60 archives holding over 13,000 downloadable papers and over 50,000 descriptions of offline papers from close to 1,000 series, as well as data about over 4,000 academic Economics department and research institutes [16]. RePEc grew to be one of the two main recipients of specialised information for academics through the Internet (surpassing the likes of Google ${ }^{9}$ ). See Table 1 below.

Data in Table 1 shows the breath of material at RePEc. Originating from publishers, increasing number items became available to the public at no charge (from $18 \%$ of all items in the digital library in 1998 to $87 \%$ in 2010). This trend witness the increasing interaction between commercial companies (i.e. journal publishing houses) and the open source community $[17,18]$. Table 1 also shows items deposited at RePEc doubling to almost one million between 2005 and 2010. An average of 55\% of these were links to working papers and the other half made up by links to journal articles (with an average of $1 \%$ being made up by books, chapters in books and software items). ${ }^{10}$ Working papers therefore constituted a key part of the RePEc digital library. However, between 1998 and 2010 items in RePEc were growing at an average 26\% p.a., with journal articles growing at a higher rate (45\% p.a.) than working papers (17\%).

become popular in other fields. For instance, Joseph Halpern (then at the Centrum Wiskunde \& Informatica) wrote to Francisco Moraiz (then at the University of St Andrews and editor of nepgth) how through his work at the Computing Research Repository or CoRR (http://arxiv.org/corr/home accessed 20/Nov/2010) left him with the impression that: "Right now [2002) there seems to be too many game theory repositories; the orginal one at Washington University (which seems somewhat moribund), the WoPEc/RePEc repository, the ERN repository, and others. I wonder if there's a way of hooking them all together, so that there is one, rather than just many." (email 22/Jul/2002).

${ }^{9}$ Peter Jasco at Péter's Digital Reference Shelf - December. See http://www.galegroup.com/free resources/reference/peter/dec.htm\#googlescholar (accessed 28/Dec/04).

${ }^{10}$ Note that only a subset of journal items are the published version of working paper items. 
Table 1: Number of Items in RePEc, 1998-2010

\begin{tabular}{|c|c|c|c|c|c|c|c|c|c|c|}
\hline $\begin{array}{l}\text { Year } \\
\text { end }\end{array}$ & $\begin{array}{l}\text { Working } \\
\text { Papers }\end{array}$ & $\begin{array}{l}\% \text { of } \\
\text { total }\end{array}$ & $\begin{array}{l}\text { Annual } \\
\text { Growth }\end{array}$ & $\begin{array}{l}\text { Journal } \\
\text { Articles }\end{array}$ & $\begin{array}{l}\% \text { of } \\
\text { total }\end{array}$ & $\begin{array}{l}\text { Annual } \\
\text { Growth }\end{array}$ & Total $^{*}$ & $\begin{array}{l}\text { Annual } \\
\text { Growth }\end{array}$ & Downloadable & $\begin{array}{l}\% \text { of } \\
\text { total }\end{array}$ \\
\hline 1998 & 54,954 & $86 \%$ & & 8,414 & $13 \%$ & & 63,629 & & 11,651 & $18 \%$ \\
\hline 1999 & 61,972 & $81 \%$ & $13 \%$ & 14,484 & $19 \%$ & $72 \%$ & 76,930 & $21 \%$ & 20,870 & $27 \%$ \\
\hline 2000 & 79,650 & $69 \%$ & $29 \%$ & 34,741 & $30 \%$ & $140 \%$ & 115,040 & $50 \%$ & 35,337 & $31 \%$ \\
\hline 2001 & 94,562 & $64 \%$ & $19 \%$ & 52,166 & $35 \%$ & $50 \%$ & 147,497 & $28 \%$ & 59,225 & $40 \%$ \\
\hline 2002 & 106,257 & $61 \%$ & $12 \%$ & 67,154 & $39 \%$ & $29 \%$ & 174,272 & $18 \%$ & 84,289 & $48 \%$ \\
\hline 2003 & 120,058 & $57 \%$ & $13 \%$ & 88,461 & $42 \%$ & $32 \%$ & 210,321 & $21 \%$ & 117,640 & $56 \%$ \\
\hline 2004 & 143,530 & $48 \%$ & $20 \%$ & 152,338 & $51 \%$ & $72 \%$ & 298,293 & $42 \%$ & 201,525 & $68 \%$ \\
\hline 2005 & 169,727 & $47 \%$ & $18 \%$ & 184,993 & $52 \%$ & $21 \%$ & 357,666 & $20 \%$ & 257,397 & $72 \%$ \\
\hline 2006 & 199,152 & $44 \%$ & $17 \%$ & 247,840 & $55 \%$ & $34 \%$ & 451,079 & $26 \%$ & 343,775 & $76 \%$ \\
\hline 2007 & 224,744 & $40 \%$ & $13 \%$ & 327,430 & $59 \%$ & $32 \%$ & 556,654 & $23 \%$ & 448,151 & $81 \%$ \\
\hline 2008 & 277,737 & $41 \%$ & $24 \%$ & 399,289 & $58 \%$ & $22 \%$ & 683,838 & $23 \%$ & 570,868 & $83 \%$ \\
\hline 2009 & 317,488 & $38 \%$ & $14 \%$ & 488,410 & $59 \%$ & $22 \%$ & 825,358 & $21 \%$ & 703,033 & $85 \%$ \\
\hline $2010^{\star *}$ & 369,322 & $39 \%$ & $16 \%$ & 566,415 & $59 \%$ & $16 \%$ & 958,995 & $16 \%$ & 831,236 & $87 \%$ \\
\hline Avg & & $55 \%$ & $17 \%$ & & $44 \%$ & $45 \%$ & & $26 \%$ & & $59 \%$ \\
\hline
\end{tabular}

Source: Own estimates based on data from http://logec.repec.org/details.htm (accessed 29 October 2010)

Notes: * - including books, chapters in books and software items; ${ }^{* *}$ - As of September, 2010.

As part of the WoPEc project and influenced by Mili's work, Krichel managed a CAS through an e-mail distribution list that carried announcements for new papers deposited at WoPEc. By 1998 the list had a membership of 700 unique e-mail addresses. Based on the growing success of RePEc, Krichel identified a need to move further the concept of an associated list to inform of new contributions. The reason being the legacy distribution list from WoPEc considered papers from all parts of the economics discipline. There was thus an opportunity to create subject specific reports, each distributed through its own list. Moreover, a system that would not only inform subscribers but also give them the opportunity to download papers upon request and free of charge.

On February 4, 1998, he wrote to the young economists discussion list, an electronic discussion forum that is now defunct, detailing his vision and hoping for some enthusiasts to act as editors of subject specific reports: 
There is a large-scale development going on to unify the provision of electronic working papers through the internet [sic], called the RePEc project, see http://netec.mcc.ac.uk/RePEc. The NBER, the US Federal Reserve Banks and WoPEc are working together in that project, and so are a few others. Currently new additions to that database are circulated through the WoPEc-announce mailing list, see http://www.mailbase.ac.uk/lists/wopec-announce/. This carries announcements for new papers. However the interest of the list is limited by the fact that it carries papers from all parts of the discipline. Despite that fact there are over 700 people on the list.

I am now thinking of opening a series of lists that would operate peer-reviewed announcement [sic]. That is each list would be headed by an editor, correspond to a subject that the editor has specified and would only receive annoucements [sic] of papers that the editor thinks fit into the subject [sic] of the list. Each editor would receive a list of new additions to RePEc each week, and would pass on the edited information to the list as (s)he sees fit. All lists put together would be called FERN (like Free Economics Research Network). They would concentrate on delivering contents, rather than administrative information or the names of the big cheeses on the editorial board. Each individual list would be called "FERN reports on XXX", where XXX is the subject stated by the editors. There is no limit to the subjects that could be covered.

This is a call for editors to come forward. As an editor, you would receive a list of additions to the RePEc dataset each week for you to filter, and pass on a selected few to your list. That would not take much of your time, and if you do not feel like sending anything, well then there would be no FERN report on your topic for that week. You will receive absolute power to manage your list as you see fit. You will need to remove dead addresses from time to time, that is all. The reason being the legacy distribution list from WoPEc considered papers from all parts of the economics discipline. There was thus an opportunity to create subject specific reports, each distributed through its own list. Moreover, a system that would not only inform subscribers but also give them the opportunity to download articles upon request and free of charge.

There are a number of good reasons why the position of editor could be attractive esp. for young economists. First you have to stay on top of the literature anyway, and that is a good way of doing so. Second, being the editor of a well edited FERN report series will raise your profile in the profession. Third, you will have the opportunity of work with other editors in faraway places and join the wider community working on the free dissemination of research material on the internet [sic].

This is just an initial call, if you would be interested in an editing position please get in touch with me privately, stating what subject area you would like to cover. If you would like 
to help with organising the list infrastructure (as kind of a super editor) I would also like to read from you.

The initial name of the project was "FERN", the Free Economics Research Network. The label FERN was invented by Bob Parks ${ }^{11}$ (Washington University) for a large scale mailing to many economists to advertise services like EconWPA, WoPEc, etc. This mailing was a one-off campaign in June 1996, long before junk mail became a plague on the Internet. The name FERN then lay dormant until Krichel's e-mail quoted above. After discussions with respondents to this e-mail, the name NEP: New Economic Papers, suggested by Sune Karlsson ${ }^{12}$ (then at the Stockholm School of Economics), was adopted. At the time, NEP was mainly used as an abbreviation for a brief experiment of economic policy in Russia in the mid 1920s.

There were a number of good reasons why a name too close to the existing Economics Research Network (ERN) was not thought to be the best solution. One was a potential threat of legal action by Social Science Electronic Publishing (SSEP ${ }^{13}$ ), who traded under the name of ERN. Second the inclusion of the word "free" was considered bad marketing. It was felt that academic economists, as target audience, would look with some suspicion something that was "freely available" and make the project look like a "poor-woman's" ERN. This never has been the objective. The aim was to be better than ERN and become the best service for rapid dissemination of recent additions to academic literature. The ethos of remaining a free service should only be perceived as an additional advantage.

Another problematic point of the initial e-mail is that it confused e-mail lists with reports. Mailing lists are technical devices. What was at stake in the creating of NEP was a new type of serial that would have issues that contained descriptive data on new additions to the RePEc working paper stock. Thus, each editor was to responsible of at least one report - as editing multiple reports was allowed and actually encouraged. The mailing list was just a means to circulate report issues.

A third problem with the initial e-mail was the promise that editing a report "would not take much of your time". This was true at the time when the e-mail was written. At that

\footnotetext{
${ }_{11}^{11}$ http://economics.wustl.edu/parks (accessed 01/Nov/10)

12 http://ideas.repec.org/e/pka1.html or http://blog.repec.org/category/repec-volunteers/page/2/ (accessed 01/Nov/10)

${ }^{13}$ SSEP's lists were established in 1994. They were re-bundled as the Social Science Research Network or SSRN (http://www.ssrn.com/, accessed 28/Dec/04). Charges for accessing their collections and subscribing to their distribution lists were introduced 'circa' 1996.
} 
time, one could typically expert 30 new papers to look at. But that soon ceased to be the case. By 2002 an editor could expect to review 300 papers per issue of nep-all. Bumper crops of over 600 papers were not unheard of. The success in attracting new collections in the digital library started to disrupt the functioning of the NEP editorial base (more below).

The initial e-mail did not state the motivation for the creation of NEP, thus we have to speculate. Reading between the lines, it appears that the main motivation was a reaction to the announcement services that were run by SSEP. The name FERN points to that, but also the reference to "big cheeses on the editorial board" as SSEP services were established and promoted by well known academics such as Michael Jensen (Harvard Business School) ${ }^{14}$. SSEP also boasted editors of established hard-copy, peerreviewed outlets and other famous economists on "advisory boards". There is no evidence of what has been the added value or actual role of these advisory boards, but the lack of a similar structure for RePEc seems to have been a concern for those setting up NEP as well.

There were two respondents of note to the initial e-mail by Kritchel. First, John S. Irons $^{15}$ (then at the Massachusetts Institute of Technology) was interested in becoming the "super editor", later called General Editor. Secondly, Vania Sena (then at the University of York) who helped Krichel to work on a general document that was to serve as a "constitution" for the service, as well as a general guide to the project. Its first version was discussed at a meeting in York on 14 February 1998. The document was thus called the York protocol. ${ }^{16}$ The first nep-all report had 32 papers and was posted by Irons on May 4, 1998. ${ }^{17}$

\section{Implementation}

The software to scan the RePEc contents and extract a list of new additions was written by José Manuel Barrueco Cruz (Universitat de Valencia) ${ }^{18}$. He also wrote software to

\footnotetext{
${ }^{14}$ See further "SSRN Celebrates its $10^{\text {th }}$ Anniversary". Available at http://ssrn.com/update/general/mjensen.html (accessed 01/Nov/2010)

${ }_{15}^{15} \mathrm{http}: / /$ www.americanprogress.org/events/2008/05/inf//ronsJohn.html (accessed 01/Nov/2010)

${ }_{16}$ Although the York protocol document went through several revisions by Krichel, Irons and Bátiz-Lazo, it was never made public. See http://openlib.org/home/krichel/papers/search .doc (accessed 01/Nov/2010). Its last known edit was dated January 24, 2001 by Bátiz-Lazo. This version is available upon request.

${ }^{17}$ http://lists.repec.org/cgi-bin/mailman/private/nep-all/1998-May/000000.html (accessed 06/Nov/2010).

${ }^{18}$ http://www.uv.es/ barrueco/ (accessed 01/Nov/2010).
} 
distribute the list of new additions to all the editors - as detailed in a central register which also acted as the NEP's web page. ${ }^{19}$ He was thus chiefly in charge of the technical infrastructure until the introduction of ernad in 2005.

The software written by Barrueco Cruz would compile a report of new working paper additions to RePEc and this file was then edited by the General Editor for "offending" content. This was distributed as a text-based e-mail report (called nep-all) to individual editors. It also formed a report in its own right, because it was---and is--deemed suitable for general consumption. Individual editors manually removed references to papers considered inappropriate to the subject area of the individual NEP report and then forward this message to subscribers with the aid of the e-mail distribution manager.

Then in late 2001 and at the initiative of Irons and Christian Zimmerman ${ }^{20}$ (then at the Université du Québec à Montréal) there was a first move to streamline the work of editors as it was getting quite burdensome to generate the reports on a purely manual system due to the growing number of online working paper series being incorporated into RePEc. Irons programmed and introduced a first version of a web interface on January $2000 .^{21}$ Karlsson then greatly improved it and produced a fully functional webbased interface to create reports. ${ }^{22}$ This "tool" had an immediate impact in reducing the time for individual editors to generate a report.

But in spite of the new tool, reports were still limited to text-based messages as editors had to "cut and paste" content into individual e-mail accounts for distribution. Between 1998 and 2010, NEP made use of three e-mail distribution managers. NEP reports were originally posted to subscribers through e-mail distribution lists administered by Mailbase ${ }^{23}$ at the University of Newcastle. Mailbase was a funded by JISC. Mailbase' remit was to explore and develop electronic exchanges between British academics. This project included the development of the software infrastructure to manage and support e-mail distribution lists. In November 2000 the service moved to a more cost effective provider at Rutherford Appleton Laboratory in Oxfordshire while the

\footnotetext{
${ }^{19} \mathrm{http}: / /$ nep.repec.org (accessed 01/Nov/2010).

$20 \mathrm{http} / / /$ ideas.repec.org/e/pzi1.html (accessed 01/Nov/2010).

21 http://lists.openlib.org/mailman/private/nep-editors/2000-February/000144.html (accessed 06/Nov/2010).

22 http://lists.openlib.org/mailman/private/nep-editors/2000-February/000362.html (accessed 06/Nov/2010).

${ }^{23}$ http://www.mailbase.ac.uk/ (accessed 25/Mar/2005). The mailbase software was retired in April 2007. See http://www.ncl.ac.uk/iss/software/e-mail/lists/MB info/ (accessed 01/Nov/2010).
} 
rights to the "Mailbase" name were kept by Newcastle University. Services for academic mailing in the United Kingdom were then to be managed by the National Academic Mailing List Service or JISCmail. ${ }^{24}$ Another important change was that e-mail lists and eannouncement service were to be hosted with the aid of an "off the shelf" package called "Listserv" 25 rather than under purpose built software as was Mailbase.

Like its predecessor at Mailbase, e-mail lists, e-discussion forums and announcements at JISCmail were really meant for the benefit of the UK academic community. Initially this posed no threat to NEP because WoPEc was also a project of JISC. The only requirement for NEP was that at least one list owner had to be a UK academic. This person was originally called the "mailbase person". Krichel took on that responsibility until October 2000 when Bernardo Bátiz-Lazo ${ }^{26}$ (then at the Open University) took the position. As NEP grew he effectively became the single biggest owner of JISCmail lists.

A review of services provided by JISCmail in May 2002, however, threatened the continuity of NEP. Although the review was satisfactory and positive for the future of NEP within JISCmail, ${ }^{27}$ Krichel and Bátiz-Lazo decided there was a real risk of JISCmail ending NEP with very little notice. They decided to migrate NEP to the same machines based at Washington University of St. Louis that hosted the US mirror of NetEc. Reports were then to be distributed using $M_{a i l m a n}{ }^{28}$, an open source (i.e. freely available) mailing list manager software.

\section{Quality and Coverage}

Work on the migration of the email distribution manager started in September 2002 and stretched itself well into 2003. Jeremiah Cochise Trinidad Christensen (then a student at Long Island University) helped Krichel. Setting up the lists on Mailman was not a problem, but getting the historic information from the, old system definitely was. Three basic problems ruined the historical record. The first was that both JISCmail and Mailbase removed parts of the headers in the archived files. In particular, the "From:" headers of intermediary machines did not appear. Many times the only date data

${ }^{24}$ http://www.jiscmail.ac.uk/ (accessed 01/Nov/2010).

$25 \mathrm{http}: / /$ www.listserve.com (accessed 01/Nov/2010).

26 http://ideas.repec.org/e/pba14.html (accessed 01/Nov/2010).

27 http://lists.openlib.org/mailman/private/nep-editors/2002-November/000938.html (accessed $06 / \mathrm{Nov} / 2010)$. At the time, NEP had 25,710 subscriptions from 9,209 unique addresses. Of these, $1,618(18 \%)$ were identified as British academics (as ending with "ac.uk").

${ }^{28}$ http://www.gnu.org/software/mailman (accessed 01/Nov/2010) 
available seems to have been the date on the mail client of the editors sending the report issue. Since time on personal computers is not well kept, dates could be well out of line. Dates of a report could be read from the contents of the report but some editors took the habit to change the ISO formatted date into something they felt looked more welcoming. As a consequence, there was a suspicion that many editors did not to a timely job on report delivery.

A second problem was that most of the time, editors would cut-and-paste from the web tool into their mail client. Character set on the clipboard would be highly dependent on the editor's locale. As a result, many of the characters in the reports were badly affected. In particular, the "handle" (i.e. the unique identifier) of individual papers was often garbled. Some editors used HTML mail clients which further added to the problem.

A third issue was that the mechanisms for filtering of handles that had already been passed on to individual editors was not as "water-tight" as one would have hoped. As a consequence some papers were presented to subject editors several times, and some editors included them twice or more times. Under these circumstances, estimating the timeliness of a report issue became almost impossible.

In tandem with the above, a fourth issue at the time was deciding on scope of individual reports. It had two elements, namely subject coverage and quality. Regarding the latter, the appropriate role of the editors was (and is) to make announcements about new on-line papers in their field with the relevant abstracts, but not to "review" the papers for quality. However, some editors had been posting calls for papers and other information through their e-mail distribution list. In discussing the content of the e-mail distribution and the need to stick solely to NEP reports, Krichel initially floated the idea of NEP developing into a peer reviewed electronic outlet. He suggested NEP having "hundreds of editors ... and each would list the papers they are most interested. If they would rank them, we would have a real community peer-review system. We could build overall recommendation strategies out of the recommendations of a lot of people, somewhat alike to what google [sic] does for web pages." ${ }^{29}$ A heated exchanged

\footnotetext{
${ }^{29}$ Krichel initially floated the idea of a peer reviewed electronic outlet to editors on November 14, 2001 (http://lists.openlib.org/mailman/private/nep-editors/2002-November/000943.html accessed 08/Nov/2010).
} 
followed through which editors rejected the idea of changing the nature of the reports. ${ }^{30}$ This discussion amongst editors confirmed that they had a uniform view that NEP could not be regarded as a vehicle for a preliminary peer review. Moreover, this discussion made clear that editors' only concern to disseminate new working papers was based on the subject matter. NEP announcements, therefore, were (and have been) selective as they rely on the editors' judgment for simple filtering [see further 19].

As far as subject coverage was concerned, there was a discussion as to whether NEP should aim for complete subject coverage for broad categories. ${ }^{31}$ The exchange touched on the emergence of anecdotal evidence suggesting that an increasing number of working papers in nep-all were not being distributed. In light of this discussion, Barrueco Cruz et al. [20] carried out an empirical assessment of NEP. Their focus was estimating the coverage ratio. That is the ratio between the number of papers out of a nep-all issue that received at least one announcement, and the papers in that some nep-all issue. As shown in Table 2 at that point in time, the number of subject reports had been growing (from 27 in 1998 to 56 at the end of 2003) while the number of nep-all report issues per year remained at circa 30 p.a. or below the desired target of one weekly issue (or some 50 reports p.a.).

The expectation was that as the number of subject reports grew there would be an improvement in the coverage ratio over time. But instead between the coverage ratio remained static at around $70 \%$, which was deplored as a "serious problem of coverage" [20]. Using a graph for data available between July 1998 and August 2002, they illustrated that the coverage ratio seemed to be negatively related to the size of the nepall. Bakkalbasi and Krichel [19] confirmed this idea using formal inferential statistics.

\footnotetext{
${ }^{30}$ Krichel rekindled the discussion of NEP becoming an electronic journal with the same result of it being turned down in March 2005 (http://lists.openlib.org/mailman/private/nep-editors/2005March/001973.html accessed 01/Nov/2010).

31 Between September 2003 and July 2004, Bátiz-Lazo and Novarese looked at the possibility of opening reports to match JEL (Journal of Economic Literature) classsification. This initiative was called "Citta d'Alba paper" (http://lists.openlib.org/mailman/private/nep-editors/2004July/001552.html acessed 08/Nov/2010). The aim was not for JEL codes to dictate NEP structure but for "gaps" to be a guide ".. to open those lists and recruit editors (and probably also be more active in attracting some collections to fill content ..." (idem). Although informative, the initiative was abandoned as there were 866 possibilities for level one and two JEL codes and the 68 reports didn't map systematically to either one.
} 
Table 2: Growth and Frequency of NEP Subject Reports, 1998-2010

\begin{tabular}{rrrrrrr} 
Year & $\begin{array}{c}\text { Number } \\
\text { of reports } \\
\text { at year } \\
\text { end }\end{array}$ & Growth & $\begin{array}{c}\text { Num of } \\
\text { issues }\end{array}$ & $\begin{array}{c}\text { Average days } \\
\text { between } \\
\text { issues }\end{array}$ & St dev & Mode \\
\hline 1998 & 27 & & 28 & 8.96 & 6.47 & 7 \\
1999 & 37 & $37 \%$ & 33 & 10.85 & 7.13 & 7 \\
2000 & 39 & $5 \%$ & 42 & 8.67 & 3.97 & 7 \\
2001 & 49 & $26 \%$ & 31 & 12.00 & 7.46 & 7 \\
2002 & 55 & $12 \%$ & 32 & 11.13 & 6.52 & 10 \\
2003 & 56 & $2 \%$ & 43 & 8.42 & 4.19 & 7 \\
2004 & 57 & $2 \%$ & 47 & 7.91 & 3.58 & 7 \\
2005 & 68 & $19 \%$ & 50 & 7.30 & 2.14 & 7 \\
2006 & 75 & $10 \%$ & 50 & 7.34 & 2.72 & 7 \\
2007 & 78 & $4 \%$ & 53 & 6.83 & 1.64 & 7 \\
2008 & 81 & $4 \%$ & 50 & 7.36 & 1.90 & 7 \\
2009 & 84 & $4 \%$ & 50 & 7.26 & 1.84 & 7 \\
$2010 *$ & 85 & $1 \%$ & 41 & 7.34 & 2.41 & 7
\end{tabular}

Source: Own estimates based on data from http://econpapers.repec.org/scripts/nep.pf? (accessed 01/Nov/2010).

The appearance of these papers added to concerns within NEP management over how to improve the coverage ratio. Another important concern around this time related to the way editors engaged with their tasks. Generating a report had remained largely unchanged from the early days of the project. The introduction of the "web tool" helped. But reports were still limited to text-based messages as editors had to "cut and paste" content into individual e-mail accounts for distribution. There was also a clear need to aid editors as the size of nep-all was growing. An initiative launched back in November 2001 for Sergei I. Parinov (then at the Siberian Branch of the Russian Academy of Sciences) ${ }^{32}$ to coordinate the creation of a new technical infrastructure had proven over ambitious and collapsed. ${ }^{33}$ Then in June 2004 and thanks to some UK government funding left over from the WoPEc project, Krichel hired Roman D. Shapiro to start the development of a new system to edit NEP reports. ${ }^{34}$

\footnotetext{
${ }^{32}$ http://ideas.repec.org/e/ppa6.html (accessed 06/Nov/2010).

33 The map for the collaboration was called "Aeroflot proposal". See http://openlib.org/home/krichel/work/aeroflot.html (accessed 06/Nov/2010).

${ }_{34}$ On 19/Jan/2004 Kritchel announced the launching of the so called "Altair project" (http://lists.openlib.org/mailman/private/nep-technicians/2004-January/000252.html accessed $01 / \mathrm{Nov} / 10$ ). This initiative envisioned replacing the "back-office" infrastructure of NEP with an AMF-based set of scripts, and a web interface that would better log the generation of report
} 
Krichel wrote a paper describing a generic infrastructure called ernad (editing reports on new academic documents). ${ }^{35}$ It was written in Perl (using LibXSLT and mod_perl) to run on Debian GNU/Linux machine (Apache 2 web server), while not being geared to a specific mailing system [15]. The report data and issue data were encoded in AMF (format for description of academic documents). ${ }^{36}$ The advantages of ernad were considered to be

- the centralisation of editor control on one system

- the separation of contents from presentation through the use of XML

- a better integration between report creation and distribution

- enabling HTML-based reports, that is, sending reports in both standardised text and HTML format (bound together by MIME multipart/alternative).

- enabling editors to sort the report result by bringing the papers they like best to the top of the issue

- reduce or even eliminate the use of distribution lists by NEP editors for anything other than NEP reports (i.e. purge of unrelated postings such as calls for papers)

- improve coverage ${ }^{37}$

The introduction of ernad had a major effect in the way NEP was run and managed. On the one hand, it provided a simple-to-use interface for the composition of reports (e.g. an easy to scroll input, allowed for easy sorting of a report's content, did a better job at pretty-printing) as well as lay the ground for the introduction of pre-sorting. ${ }^{38}$ On

issues. (http://wotan.liu.edu/home/krichel/work/altai job.html accessed 01/Nov/10). Later the "Seabro projected", launched on January 2009 by Krichel and John Q. Sillari, aimed to rationalise and make easier to update the software behind ernad (see http://lists.openlib.org/mailman/private/nep-editors/2009-January/003257.html accessed 06/Nov/2010).

${ }^{35}$ See also "Gentilly paper" (http://openlib.org/home/krichel/work/gentilly.html accessed 06/Nov/2010).

${ }^{36}$ Ernad documentation (http://openlib.org/home/krichel/work/ernad.html accessed $06 / \mathrm{Nov} / 2010)$.

${ }^{37}$ There were 296 nep-all reports issued between January 2005 and October 2010 (http://nep.repec.org/lossage/ accessed 06/Nov2010). Each averaged 360 individual papers, of which 54 were "lost" (not included in any individual report). That represented a coverage of $87 \%$ as opposed to the 70 to $80 \%$ identified in Barrueco Cruz et al. [20] J. M. Barrueco Cruz, T. Krichel, and J. C. Trinidad Christensen, "Organizing Current Awareness in a Large Digital Library," in Users in the Electronic Information Environments, Espoo, Finland, 2003..

${ }^{38}$ Between 2004 and 2005, Krichel and Nisa Bakkalbasi (Yale University http://www.library.yale.edu/about/departments/ecollections/staff responsibilities.htm|\#nb 
the other hand, it restricted editorial freedom: editors no longer sent e-mails to lists but after making their selection on a web interface only one e-mail address (ernad@nep.repec.org) posted to subscribers through individual distribution lists. ${ }^{39}$ Editors could not add unsolicited material (e.g. announcements, calls for papers) at the end of the report. Neither could they change dates of issue.

The discussion now turns to explore how ernad changed NEP's management structure in greater depth.

\section{Governance}

Barrueco Cruz et al. [20] also suggest that editors' performance need to be better policed. One way to do that was to look at the time an editor took to create an issue, that is, the difference between the moment nep-all was issued and an individual report posted. Data in Table 2 show the time between nep-all issues increasing between 1998 and 2002 (reaching its maximum of 12 days, 7.46 st. dev. in 2001). Anecdotal evidence suggested the increase amongst individual reports was even higher. However, collecting such data systematically was impossible because of poor archive keeping. Other suggestion from the work documented at Barrueco Cruz et al. [20] was sharing of the editor job between editors, or the creation of a formal hierarchy.

On July 2003 Krichel launched "nep-technicians". ${ }^{40}$ This was the first step in the overall direction pointed by Barrueco Cruz et al. [20] as this list created a dedicated space for NEP bigwigs. Introducing a formal hierarchy took a bit longer. For much of its lifetime, NEP was formally lead by a single person known as the General Editor. This

accessed 06/Nov/2010) developed a system that would use statistical learning techniques to learn the preference of individual editors. This routine was incorporated into the ernad web editing interface on August 2005. As a result the nep-all report ranked individual papers based on editor's 13 month usage history (through a combination of individual words out of the contents from titles, author names, abstracts, classification data and the id of the RePEc series or handle). Editors were then free to add, ignore or re-rank these suggestions. The idea behind presorting was not to replace editors (or make them lazy) but to invite them to examine some papers more closely than others. See further Krichel [21] T. Krichel, "Information Retrieval Performance Measures for a Current Awareness Report Composition Aid," Information Processing \& Management, vol. 43, no. 4, pp. 1030-1043, $2007 .$.

${ }^{39}$ The editor's own e-mail was used in the "reply to" field. On October 2008, e-mail distribution was complemented with the introduction of RSS feeds (http://lists.openlib.org/mailman/private/nep-editors/2008-October/003188.html accessed 06/Nov/2010).

${ }^{40}$ The original recruits were Bátiz-Lazo, Karslon, Barrueco-Cruz, Kritchel and Trinidad Christensen. See http://lists.openlib.org/mailman/private/nep-technicians/2003-July/000001.html (accessed 01/Nov/2010). 
post was occupied by Irons between June 1998 and October 2000, and by Bátiz-Lazo between October 2000 and December 2004.

Initially the General Editor would ensure that content added to RePEc was suitable for NEP reports. For instance, that content was free of unwanted material (either machine- or man-generated). Another common occurrence were papers that had been previously submitted re-appearing, say as a result of two authors from different institutions each submit the same paper to RePEc through their local working-paper series. These were situations where it was either impossible for the computer to determine if a paper was really new or the computational power to deal with them was too costly. Whatever the case there was a need for human intervention, ideally by the General Editor, to act before individual editors were confronted with such a situation.

Alongside the issue of preparing nep-all, in the early days of the project, a fairly major task of the General Editor was recruiting volunteers to man new subject-specific reports. At the beginning, expanding the number of reports and finding good people to act as editor was an uphill battle. In the midst of the so called "dot-com" bubble, institutions had to be persuaded about the benefits of lending their collections while individuals had to allocate scarce research time for a project of unproven reputation. Not surprisingly and but for a couple of exceptions, the first editors were either doctoral students in economics or young faculty members.

Other tasks of the General Editor included overseeing the performance of individual editors, liaising with the technical support team at RePEc, Mailbase and JISC as well as representing NEP and its editors within the RePEc community. NEP grew from strength to strength but so did the tasks and demands on the time of the General Editor. Part of the ethos of RePEc was and has been to avoid a single point of rupture and as a result, the appointment of Marco Novarese ${ }^{41}$ (Universitá degli Studi del Piemonte Orientale) as Deputy General Editor in June 2003 had been long in the make.

The introduction of ernad in January 2005 was accompanied with the first major change in NEP's governance structure. ${ }^{42}$ NEP would then be formally led by group of people who would be formally assigned specific responsibilities, namely:

- Managing Director - The person who oversees the expansion of NEP. S/he was given the power to appoint new editors and create new reports. This person often

\footnotetext{
${ }^{41} \mathrm{http}: / /$ econpapers.repec.org/RAS/pno2.htm (accessed 06/Nov/2010).

42 http://nep.repec.org/etc/governance.html (accessed 01/Nov/2010).
} 
acts as point of contact with editors (for matters other than performance), subscribers and the wider RePEc community. Bátiz-Lazo became the Managing Director at its introduction in January 2005 until he retired in April 2007. ${ }^{43}$ Novarese then assumed this role.

- General Editor - The person who every week ascertains that content available to individual editors is free of unwanted material (either machine- or man generated). Novarese became the first General Editor in January 2005. Since no other editor wanted to take this post when Bátiz-Lazo retired as Managing Director in 2007, then Novarese continued with this function.

- Performance Controller - The person who oversees the performance of NEP. $\mathrm{S} /$ he has the power to retire subject editors who don't issue reports in a timely manner. The first person to act as controller was Christian Calmès ${ }^{44}$ (Université du Québec en Outaouais). ${ }^{45}$

- Wizard - The person that provides technical support for NEP and its infrastructure. Barrueco Cruz chiefly took on this task from 1998 until the introduction of ernad in January 2005, afterwards Krichel who took over the role.

As mentioned, all NEP editors are volunteers. Most of them dedicating part of their research time to furnish the wider community with specialised reports in a topic area. Over time there was a need to attract new editors as a result of new reports being opened by the General Editor (and then the Managing Editor), because an standing editor retired or because an editor was disciplined and suspended of his/her responsibilities by the Controller. In case of an opening, it was advertised through the subscriber base of the particular report as it was deem that this was a group of people appreciative of the services provided by NEP. Alternatively, new editors could be recruited by individuals freely approaching the Managing Director with proposals of new NEP reports.

\footnotetext{
${ }^{43}$ http://lists.openlib.org/mailman/private/nep-editors/2007-April/002725.html (accessed 06/Nov/2010).

${ }^{44} \mathrm{http}: / /$ econpapers.repec.org/RAS/pca19.htm (accessed 06/Nov/2010).

45 To support this function a "delay report" was introduced by Krichel on 27 November 2006 (http://lists.openlib.org/mailman/private/nep-technicians/2006-November/002411.html accessed $01 / \mathrm{Nov} / 2010)$. This report quantified the gap between the moment nep-all was issued and an individual report posted (http://nep.repec.org/delay/ accessed 01/Nov/2010).
} 
Whichever the case, the introduction of ernad saw the formalisation of appointments. A new system replaced the ad hoc approach followed until then. The new procedure envisioned the formation of a Selection Committee made out of a group of standing editors, chaired by the Managing Director, who would meet (electronically) to select between candidates for an opening as editor of NEP. Selection was based on evidence of commitment to the subject area as demonstrated by the candidate's curricula - where sometimes relevant industry experience has been preferred over academic credentials.

Other ongoing issue addressed by the change in governance was how to deal with contributions in languages other than English. Dealing with these represented an important element to improve the coverage ratio. For some reports (such as those focusing in Latin America or the Confederation of Independent States) it was considered a strength to carry relevant research of non-English sources (e.g. Spanish or Russian). But including non-English sources added to the pre-ernad work of all editors. Arguments for and against were varied. Some editors wanted to focus on freely accessible research to the widest possible audience. English being the "lingua franca" of academia, they argued, non-English contributions should be discouraged and, for some, even banned. In light of the paradox a decision was taken by Bátiz-Lazo and Novarese that nonEnglish contributions should not be encouraged but that submissions would be accepted and the final decision to include them in a report taken by individual editors.

\section{Discussion and Conclusions}

The NEP project works as a simple refereed electronic announcement service for each specific subject list. It is truly international in membership, subscription and content. Moreover, it is an outlet that combines research from top academics such as those based at the University of Pennsylvania, University of Cambridge, University Paris I (Panthéon-Sorbonne), "blue chip" institutions such as the World Bank, International Monetary Fund, Bank of Italy and Bank of England with other of the less known research active centres and individuals. The success of NEP to achieve its aim has been startling, as shown by its growth in scale and scope: as of December 2004, NEP had 57 subject area reports and had distributed over 104,662 items listed in RePEc. As of March 2005, NEP encompassed 61 reports (an increase of $22 \%$ since April 2002) and a membership of 13,649 unique addresses (an increase of $148 \%$ since July 2001). These figures doubled in the following five years as in November 2010, NEP had 87 reports and a membership of 62,866 subscriptions from 28,988 unique addresses. NEP thus acts as a 
forum for academics, academic institutions and researchers in industry to share ideas and their research with peers elsewhere in the world.

NEP is different to other current awareness services (CAS) in two fundamental aspects. First, NEP is based on a digital library (called RePEc). A second differentiating aspect of NEP is being a human-mediated CAS, that is, NEP is generated from an interaction of computer applications and human decision making throughout. All people involved in NEP work as volunteers using source data which is also freely available. But the fact that NEP is freely available is an added feature of its service rather than a differentiating characteristic.

NEP has a simple, two stage workflow. In the first stage, a computer program generates a list of new additions to RePEc. A human then examines that list to filter out papers that are new to RePEc but are not new. This list (called nep-all) is circulated electronically to editors who scan it for papers that pertain to a certain subject. With the assistance of a computer application editors distribute electronically their selection in the form of an issue of a subject specific NEP report.

NEP's technical infrastructure actively makes use of open source software to facilitate interaction between users. Open source is not a pre-condition as there are many commercial alternatives. But in spite of this, NEP shares a number of features with many open source developments [as suggested by 17]:

- It is the result of the vision and continued enthusiasm of Thomas Krichel. The extent to which the plans envision in his original e-mail have crystallised is remarkable. However, his authority has not gone unchallenged. Most notably when editors were reluctant for NEP to evolve into an online journal.

- It is geared to the "smartest customers" as the most "sophisticated" users or academics and practitioners who will be active in making contributions in forms of papers, suggesting new reports and even contribute to the running of NEP. "Most ignorant" users will be recruited by a deputy (such as NEP editor or research assistant in his/her university) rather than directly. They will be passive. NEP's 30,000 strong unique e-mail subscriber base is most likely made out of "most ignorant" users.

- There is a small élite or 'core cadre' composed of less than ten editors who actively make or have made important contributions to day-to-day running and 
managing its evolution. Moreover, only some of the members of this élite have advance software programming skills but any one of them would have faced some programming task in a non-Windows environment (such as performing routines in languages favoured in open source such as PEARL).

- Its technical infrastructure is modular so contributions can be clearly traced to individuals making direct (i.e. programmers and editors) or indirect (i.e. mailman) contributions.

- Reports (rather than code) collecting recent additions to the academic literature are freely available. Neither are contributors (whether institutions or individuals) charged for uploading and disseminating their work.

- Incentives for individuals to participate as editors are clearly rooted in the visibility of an individual's performance. "Ego gratification incentive" is big as a large subscriber base results in direct peer recognition.

But unlike open source software:

- Different variants have not emerged. NEP is the only announcement service for RePEc and the only human mediated current awareness service for economics and related areas on the Internet. This might portray NEP closer to what has been described as a platform for multi-sided markets than an open source software.

- Contributing to NEP (and particularly the coding of its platform) is highly idiosyncratic. Reducing the time involved in editing the reports was critical to see the project move forward. Opportunity cost of (research) time for individual editors is very low. This is not the case for programmers, who at times had to devote many months to developing specific applications (to the extent that research income had to be deviated to attract a suitable individual). NEP has been unsuccessful in attracting large number of programmers. Indeed, only Krichel and Barrueco Cruz have consistently supported the programming of dedicated software.

- Both membership and usage are important. NEP facilitates interaction between geographically remote members of the academic community. It is strongly focused on economics, but as this field also feeds into business and management, some related areas have been added (such as accounting, 
finance, business history and marketing) while attempts to draw others epistemologically distinct failed miserably (e.g. critical management). Hence gains from NEP accrue to usage from within a community that has means of identifying its boundaries. So although membership is open to all, not everyone will be likely to make use of NEP or indeed be attracted to it.

- The community around NEP increasingly behaved like around conventional peer-reviewed outlets, carefully choosing their reports and the contents they would publish. It evolved from a largely non-hierarchical community to develop similar structure of an editorial board. But as mentioned, in this process the community rejected challenging established outlets (as for many editors printed journals were linked to promotion).

\section{References}

[1] J. Abbate, "Privatizing the Internet: Competing Visions and Chaotic Events, 1985-1997," IEEE Annals of the History of Computing, vol. 32, no. 1, pp. 10-22, 2010.

[2] J. Dongarra, G. H. Golub, E. Grosse et al., "Netlib and NA-Net: Building a Scientific Computing Community," IEEE Annals of the History of Computing, vol. 30, no. 2, pp. 3041, 2008.

[3] D. A. Grier, and M. Campbell, "A Social History of Bitnet and Listserv, 1985-1991," IEEE Annals of the History of Computing, vol. 22, no. 2, pp. 32-41, 2000.

[4] M. Campbell-Kelly, From Airline Reservations to Sonic the Hedgehog: A History of the Software Industry, Cambridge, MA: The MIT Press, 2003.

[5] W. Aspray, and P. E. Ceruzzi, The Internet and American Business, Boston MA: MIT Press, 2008.

[6] B. Elzen, and D. Mackenzie, "The Social Limits of Speed: The Development and Use of Supercomputers," IEEE Annals of the History of Computing, vol. 16, no. 1, pp. 46-61, 1994.

[7] A. L. Russell, "Dot-Org Entrepreneurship: Weaving a Web of Trust," Enterprises et Histoire, vol. 51, pp. 44-56., 2008.

[8] H. Varian, and R. C. Schonfeld, JSTOR: A History, Princeton NJ: Princeton University Press, 2003.

[9] C. M. Kelty, Two Bits: The Cultural Significance of Free Software and the Internet, Durham, NC: Duke University Press, 2008.

[10] D. Tapscott, and A. D. Williams, Wikinomics: How Mass Collaboration Changes Everything, New York: Portfolio (Penguin Group), 2006.

[11] A. Akera, "Communities and Specialized Information Businesses," The Internet and American Business, W. Aspray and P. E. Ceruzzi, eds., pp. 423-47, Cambridge MA: The MIT Press, 2008.

[12] T. Krichel, and C. Zimmermann, "The Economics of Open Bibliographic Data Provision," Economic Analysis and Policy, vol. 39, no. 1 (March), pp. 49-52, 2009.

[13] T. Krichel, and H. Chu, "NEP Current Awareness Service of the RePEc Digital Library," Digital Libraries Magazine, vol. 9, no. 12, 2003.

[14] J. Cortada, The Digital Hand (vol. 3), Oxford and New York: Oxford University Press, 2008. 
[15] T. Krichel, "Quality Assessment of an Academic Current Awareness System: The Case of NEP ", Universidad Carlos III, 2007.

[16] S. Karlsson, and T. Krichel. "RePec and S-WoPEc: Internet Access to Eletronic Preprints in Economics," November 1, 2010; http://openlib.org/home/krichel/papers/lindi.html.

[17] J. Lerner, and J. Tirole, "Some Simple Economics of Open Source," Journal of Industrial Economics, vol. 50, no. 2, pp. 197-234, 2002.

[18] D. S. Jeon, and J. C. Rochet, "The Pricing of Academic Journals: A Two-Sided Market Perspective (WP 09-098)," Ecole d'économie de Toulouse, 2009.

[19] N. Bakkalbasi, and T. Krichel, "Developing a Predictive Model of Editor Selectivity in a Current Awareness Service of a Large Digital Library," Library and Information Science Research, vol. 27, no. 4, pp. 240-252, 2005.

[20] J. M. Barrueco Cruz, T. Krichel, and J. C. Trinidad Christensen, "Organizing Current Awareness in a Large Digital Library," in Users in the Electronic Information Environments, Espoo, Finland, 2003.

[21] T. Krichel, "Information Retrieval Performance Measures for a Current Awareness Report Composition Aid," Information Processing \& Management, vol. 43, no. 4, pp. 1030-1043, 2007. 